\title{
O Pré-Natal Psicológico como Programa de Prevenção à Depressão Pós-Parto
}

\author{
Natália Maria de Castro Almeida \\ Hospital das Clínicas da Universidade de São Paulo, \\ SP, Brasil.
}

\author{
Alessandra da Rocha Arrais \\ Universidade de Brasília, \\ Brasília, DF, Brasil.
}

Resumo: O pré-natal psicológico (PNP) é uma prática complementar ao pré-natal tradicional, voltado para maior humanização do processo gestacional, e se propõe a prevenir situações adversas potencialmente decorrentes desse processo. O objetivo da pesquisa foi avaliar a eficácia do PNP na prevenção à depressão pós-parto (DPP) em gestantes de alto risco internadas em um hospital público, em Brasília. Optou-se pelo delineamento metodológico da pesquisa-ação. A pesquisa foi realizada com 10 gestantes de alto risco, sendo que cinco delas participaram do PNP (grupo A) e cinco não participaram do PNP (grupo B). Os instrumentos utilizados foram: perfil gestacional, perfil puerperal, questionário avaliativo, sessões e materiais produzidos no grupo de PNP, Inventário Beck de Depressão e Ansiedade (BDI, BAI) e Escala COX. Foi utilizado como procedimento deste trabalho a análise mista dos resultados. Os resultados foram comparados entre os dois grupos e verificou-se que ambas colaboradoras encontravam-se vulneráveis, apresentando vários fatores de risco, portanto com tendência a desenvolver a DPP, entretanto, somente as colaboradoras do grupo B apresentaram DPP. Esses achados sugerem que o pré-natal psicológico associado a fatores de proteção presentes na história das grávidas pode ajudar a prevenir a DPP. Defende-se que a assistência psicológica na gestação, por meio da utilização do PNP, é importante instrumento psicoprofilático que deve ser implementado como uma política pública em contextos da saúde.

Palavras-chave: Atenção Pré-Natal, DPP, Psicoprofilaxia, Gestação de Alto Risco.

\section{The Psychological Prenatal Program as a Prevention Tool For Postpartum Depression}

\begin{abstract}
The Psychological prenatal program (PNP) is a complementary practice to traditional prenatal toward greater humanization of the gestational process, and aims to prevent potentially adverse situations during pregnancy and postpartum. The objective of the research was to investigate the effectiveness of the PNP in preventing postpartum depression (PPD) in high risk pregnant women in a public hospital in Brasilia. Action research methodology was chosen. The survey was conducted with 10 high-risk pregnant women: 05 of them participated in the PNP held in that maternity (group A) and 05 did not (group B). The instruments used were: gestational profile, puerperal profile, evaluative questionnaire, sessions and materials produced in the PNP group, Beck Depression and Anxiety Inventory (BDI, BAI) and COX Scale. This was a multi-methodological approach. The results were compared between the two groups and it was found that both groups of participants were vulnerable to develop PPD; however, only those in the control group (group B) showed PPD. These findings suggest that prenatal psychological factors associated with protection present in the history of pregnant women may help to prevent PPD. It is argued that psychological assistance during pregnancy, through the use of PNP, is a psycoprophylactic important tool that should be implemented as a public policy at health services and prenatal care.
\end{abstract}

Keywords: Psychological Prenatal, Postpartum Depression, Psychoprophylaxys, High-risk Pregnancy. 


\title{
El Programa Prenatal Psicológico como Prevención de la Depresión Posparto
}

\begin{abstract}
Resumen: El prenatal psicológico (PNP) es una práctica complementaria a la asistencia prenatal tradicional, volcado a una mayor humanización del proceso de gestación, y tiene como objetivo prevenir situaciones potencialmente adversas durante el embarazo y después del parto. El objetivo del estudio fue investigar la efectividad de la PNP en la prevención de la depresión posparto (PPD) en mujeres que tuvieron embarazo de alto riesgo en un hospital público de Brasilia. Fue elegida la metodología de investigación-acción. La encuesta se llevó a cabo con 10 mujeres que tenían embarazos de alto riesgo; 05 de ellas participaron en el PNP durante su maternidad (grupo A) y 05 no hicieron uso o participaron en el PNP (grupo B). Los instrumentos utilizados fueron: perfil gestacional, perfil puerperal, cuestionario de evaluación, sesiones y materiales producidos en el grupo del PNP, Inventario Beck de Depresión y Ansiedad (BDI, la BAI) y Escala de COX. Fue utilizado como procedimiento de este trabajo el análisis mixto de los resultados. Los resultados de los dos grupos se compararon y se encontró que todos los participantes eran vulnerables a desarrollar PPD; sin embargo, solo aquellos en el grupo control (grupo B) mostraron PPD. Estos hallazgos sugieren que los factores psicológicos prenatales asociados con la protección presente en la historia de las mujeres embarazadas pueden ayudar a prevenir el PPD. Se argumenta que la asistencia psicológica durante el embarazo, a través del uso del PNP, es una herramienta importante que debería implementarse como una política pública en los servicios de salud y atención prenatal.
\end{abstract}

Palabras clave: Psicología Prenatal, La Depresión Posparto, Psicoprofilaxia, Embarazo de Alto Riesgo.

\section{Introdução}

Para algumas mulheres a gravidez é um evento desejado e planejado, para outras, esse processo é raramente planejado, nem sempre marcado por alegrias e realizações (Rosenberg, 2007), sendo comum nessa fase o surgimento de sentimentos conflitantes tanto em relação ao bebê quanto à própria vida da gestante (Chiattone, 2007).

Entre os transtornos psíquicos da puerperalidade, destaca-se a depressão pós-parto (DPP). De acordo com o Manual Diagnóstico e Estatístico de Transtornos Mentais (American Psichyatric Association, 2002), a depressão pós-parto (DPP) caracteriza-se pela presença de humor deprimido ou perda de interesse e prazer por quase todas as atividades (Episódio Depressivo Maior), que se manifesta duas semanas após o parto. A ocorrência de transtornos depressivos no puerpério é alta. De acordo com dados do Ministério da Saúde (Brasil, 2006), $70 \%$ das pacientes apresentam sintomas depressivos que caracterizam o blues puerperal, estado depressivo mais brando e transitório marcado por fragilidade, hiperemotividade e sentimentos de incapacidade.
De acordo com Chiattone (2007), 10 a 16\% das pacientes preenchem critérios para o diagnóstico de DPP, que merece maior atenção. Há relatos de que 50 a $90 \%$ dos casos de DPP no mundo não são sequer detectados (Brasil, 2006). Diante da gravidade deste transtorno psíquico e, observada a necessidade de adaptação que uma puérpera precisa enfrentar, faz-se válida a utilização de recursos que tentem prevenir este distúrbio. O pré-natal psicológico (PNP) é um desses recursos, cuja abordagem diferencia-se dos cursos para gestantes. Trata-se de um novo conceito em atendimento perinatal, voltado para uma maior humanização do processo gestacional, do parto e de construção da parentalidade (Arrais, Cabral, \& Martins, 2012; Bortoletti, 2007a).

Este estudo teve por objetivo avaliar a eficácia do PNP na prevenção à DPP em gestantes de alto risco internadas em um hospital público de referência em Brasília. As pacientes foram distribuídas em dois grupos: grupo A (gestantes participantes do PNP) e grupo B (gestantes não participantes do PNP) e avaliadas quanto à presença ou ausência do diagnóstico, quatro semanas após o parto. Foi utilizada a Psicologia Positiva como referencial teórico que 
propõe um olhar voltado ao potencial de cada indivíduo, ajudando a identificar e fortalecer os fatores que permitem a redução da incidência e a prevenção de patologias secundárias a condições adversas de vida (Oliveira, \& Nakano, 2011).

\section{Pré-natal psicológico (PNP)}

Durante a gestação, observam-se várias alterações no comportamento feminino e na vida do casal, as quais envolvem aspectos sociais, familiares, conjugais, profissionais e, principalmente, pessoais. Nessa fase, é comum que o humor tenha uma característica instável podendo resultar no surgimento de sentimentos conflitantes tanto em relação ao bebê quanto à vida da gestante (Chiattone, 2007).

É de grande importância a realização do pré-natal, conforme destacam Baptista e Furquim (2009) e Bortoletti (2007b), visando a prevenção dos problemas gestacionais e o controle de agravantes psicológicos. Durante esse período ocorre ainda o preparo físico e psicológico para o parto e a maternidade, proporcionando um ambiente adequado a uma vivência positiva pela gestante (Rios, \& Vieira, 2007). Nesse contexto, o psicólogo com formação específica é o mais indicado para atuar em programas de psicoprofilaxia, na medida em que aborda questões relativas a alterações emocionais capazes de atenuar as angustias próprias deste período (Bortoletti, 2007a), além de considerar aspectos que não apenas os biológicos.

\section{Gestação de alto risco}

De acordo com o Ministério da Saúde (Brasil, 2012), a gestação é considerada um fenômeno fisiológico, devendo ser vista tanto para as gestantes quanto para a equipe médica como parte de uma experiência de vida saudável que envolve mudanças físicas, sociais e emocionais. Segundo o Manual Técnico de Gestação de Alto Risco (Brasil, 2012), apesar da maioria das gestações evoluir sem nenhuma intercorrência, há gestantes que, por serem portadoras de alguma doença, apresentam maior probabilidade de evolução desfavorável, as chamadas "gestantes de alto risco".

A gestação é considerada de alto risco quando há a existência de fatores que impliquem riscos tanto para a mãe quanto para o feto, a saber: trabalho de parto prematuro, síndromes hipertensivas da gestação, diabetes gestacional, amniorrexe prema- tura, má-formação fetal, óbito fetal, entre outras complicações (Baptista, \& Furquim, 2009).

\section{Transtornos psíquicos no puerpério}

O puerpério é um período marcado pela saída da placenta no momento do parto, prolongando-se até a retomada do organismo materno às condições antes do parto, o que envolve processos anatômicos, fisiológicos e bioquímicos (Baptista, \& Furquim, 2009). De acordo com o Ministério da Saúde, esse período pode ser compreendido em três fases: o puerpério imediato que inicia no primeiro e vai até o décimo dia após o parto; em seguida, o puerpério tardio, que abrange desde o décimo até o quadragésimo quinto dia, e, por último, o puerpério remoto, aquele que vai além do quadragésimo quinto dia, ou seja, termina quando a mulher retorna a sua função reprodutiva (Brasil, 2001).

Conforme complementa Higuti e Capocci (2003), o puerpério é marcado por um período rico e intenso de vivências emocionais para a puérpera, de grande risco psíquico na vida de uma mulher, nas quais transformações sofridas tanto no aspecto biológico quanto relacionado à adaptação das exigências características do período pós-parto acabam tornando a mulher mais vulnerável a desencadear um transtorno mental.

Os transtornos mentais no pós-parto incluem: transtornos de ansiedade - devido à existência de sentimentos ambivalentes intensos na maternidade; transtorno afetivo bipolar - doença crônica e recorrente que apresenta características do episódio depressivo maior; transtornos psicóticos - incidindo em cerca de 1 a $2 \%$ das puérperas, sendo caracterizado por intensa labilidade do humor, agitação psicomotora e ideação paranóide de base alucinatória e os transtornos depressivos (Yamaguchi, Pita, \& Martins, 2007).

De acordo com o Manual Técnico de Saúde da Mulher (Brasil, 2006), outro transtorno mental comum no período puerperal é o baby blues, que acomete de 50 a $70 \%$ das puérperas, sendo definido como estado depressivo mais brando, com surgimento geralmente no terceiro dia do pós-parto. Esse período caracteriza-se por fragilidade, hiperemotividade, alterações do humor, falta de confiança em si e sentimentos de incapacidade, e tem remissão espontânea em duas semanas.

O presente trabalho enfatizará a DPP que, de acordo com Santos (2001) e Rosenberg (2007), apresenta uma incidência de até $20 \%$ dos casos após o parto no Brasil, podendo este índice sofrer um aumento 
até 30 a $40 \%$, se considerarmos mulheres com perfil socioeconômico baixo e atendidas no Sistema Único de Saúde (Lobato, Moraes, \& Reichenheim, 2011). Por ser 0 alvo de estudo da presente pesquisa, será apresentada mais detalhadamente a seguir.

\section{Depressão pós-parto}

O nascimento de uma criança representa o rompimento do vínculo relacional entre a mãe e o bebê intraútero. Este processo de separação pode desencadear vivências depressivas e psicóticas pela mãe, reativadas por conflitos e lutos mal-elaborados durante a infância (Alt, \& Benetti, 2008), entre outros motivos.

Segundo o DSM-IV (American Psichyatric Association, 2002), a DPP é um episódio de depressão maior, que ocorre dentro das quatro primeiras semanas após o parto, durante as quais há a presença de um humor deprimido ou perda de interesse ou prazer por quase todas as atividades (anedonia). O indivíduo também deve experimentar pelo menos quatro sintomas adicionais, extraídos de uma lista que inclui alterações no apetite ou peso, do sono e da atividade psicomotora, diminuição da energia, sentimentos de desvalia ou culpa.

De acordo com Arrais (2005), a puérpera pode apresentar um profundo retraimento e isolamento social, principalmente se ocorrer uma quebra muito grande entre aquilo que a gestante imaginava ser, tanto em relação ao bebê idealizado quanto a sua própria figura materna. Ainda podem surgir sentimentos ambivalentes relacionados às dúvidas $\mathrm{e}$ medos inerentes a esse momento (Bortoletti, 2007b), devido ao não suprimento das expectativas do mito da mãe perfeita (Azevedo, \& Arrais, 2006).

A DPP tem importantes consequências sociais e familiares, sobretudo para a tríade mãe-pai-bebê, a saber: problemas conjugais, atraso no desenvolvimento do bebê e grande sofrimento psíquico para a mãe, inclusive com risco aumentado para o suicídio, entre outros (Ramos, \& Furtado, 2007). A falta de informação pode gerar expectativas e crenças sobre a sua nova condição, desencadeando sintomas de ansiedade e depressão (Baptista, \& Furquim, 2009), sendo que o impacto na vida dos envolvidos, requer um trabalho não só remediativo, mas também preventivo, a fim de evitar este grave transtorno.

Ciente dos fatores que envolvem a DPP e observada a necessidade de adaptação que uma puérpera precisa enfrentar, nada mais válido do que a utilização de um instrumento que tente prevenir este distúrbio, como o PNP. A DPP pode dificultar o estabelecimento do vínculo afetivo seguro entre mãe e bebê, podendo interferir nas futuras relações interpessoais estabelecidas pela criança, quando não adequadamente diagnosticada e tratada (Arrais, 2012; Bortoletti, 2007b; Klein, \& Guedes, 2008). Desse modo, considerando que as consultas de pré-natal auxiliam a equipe multidisciplinar a identificar os fatores de risco e de proteção para a DPP, proporcionando às gestantes melhores condições de enfrentamento, esse tema assume grande importância clínica.

\section{Fatores de risco da depressão pós-parto}

Diversos fatores de risco contribuem para o desencadeamento da DPP: gestante solteira, conflitos conjugais, histórico familiar de depressão, antecedente de transtornos depressivos, gravidez não programada, frágil suporte social e eventos de vida negativos na gravidez (Arrais, Mourão, \& Fragalle, 2014; Bortoletti, 2007b Pereira, \& Lovisi, 2008; Yamaguchi, Pita, \& Martins, 2007). Outros fatores de risco precisam ser considerados: gestante com menos de 17 anos ou mais de 40 anos, dificuldade com crises evolutivas ou acidentais, ser usuária de drogas ou álcool, tratamento ou hospitalização psiquiátrica anterior, histórico obstétrico de risco (aborto, prematuridade, placenta prévia, natimorto, más-formações), histórico familiar de doença mental e mudanças recentes no ambiente familiar ou previstas para breve (Rosenberg, 2007), assim como a idealização do bebê e da maternidade, em função de decepção e frustração que esta idealização pode acarretar (Arrais, 2005). Dessa forma, o aconselhamento e o esclarecimento adequados podem ser de ajuda imediata e servir como prevenção ao aparecimento de transtornos psicológicos.

\section{Fatores de proteção da depressão pós-parto}

Os fatores de proteção, definidos por Moraes, Pinheiro, Silva, Horta, Sousa e Faria (2006), são condições do próprio indivíduo que podem contribuir para uma melhor resposta a determinados eventos de riscos: expectativa de sucesso no futuro, senso de humor, otimismo, autonomia, tolerância ao sofrimento, assertividade, estabilidade emocional, enga- 
jamento nas atividades, comportamento direcionado para metas, habilidade para resolver problemas e boa autoestima. Constituem fatores de proteção para a DPP: o apoio de outra mulher, detecção precoce da depressão (Ruschi, Sun, Mattar, Chambô Filho, Zandonade, Lima, 2007), suporte social, boa relação conjugal e suporte emocional do companheiro (Arrais, 2005; Frizzo, \& Piccinini, 2005), estabilidade socioeconômica, sistema de apoio familiar (Rosenberg, 2007) e um trabalho de prevenção, como o PNP (Bortoletti, 2007a).

$\mathrm{O}$ conhecimento dos fatores de risco e de proteção da DPP é importante para o planejamento e execução de ações preventivas, uma vez que, conforme mencionam Zinga, Phillips e Born (2012), a intervenção precoce, utilizando uma estratégia psicoterapêutica específica entre as gestantes, pode resultar em uma redução significativa na sintomatologia depressiva. Dessa forma, sabendo-se que a promoção da integridade biopsicossocial da gestante pode ser assegurada por meio de um acompanhamento cuidadoso das mães, o trabalho de equipe torna-se essencial (Rosenberg, 2007).

O objetivo deste estudo foi avaliar a eficácia do PNP na prevenção à DPP em gestantes de alto risco internadas em um hospital público de referência, em Brasília. De forma específica, buscou-se: a) descrever os fatores de risco e de proteção para a DPP em gestantes de alto risco de um hospital público, em Brasília; b) identificar níveis de DPP destas mulheres encontrados no puerpério; c) conhecer a avaliação do PNP na perspectiva das gestantes que participaram do grupo do PNP; d) identificar a eficácia do pré-natal psicológico na redução dos fatores de risco ou na proteção para o desenvolvimento da DPP.

\section{Método}

O presente trabalho é um recorte de um projeto de pesquisa maior intitulado "O Pré-natal psicológico como programa de prevenção a depressão pós-parto”. Foi aprovado pelo Comitê de Ética em Pesquisa da Secretaria de Estado de Saúde do Distrito Federal Fundação de Ensino e Pesquisa em Ciências e Saúde (FEPECS), em abril de 2012, sob o Parecer $n^{\circ} 085 / 2012$ e o Projeto $n^{\circ} 025 / 12$.

Para que os objetivos pudessem ser atingidos, o método utilizado foi a pesquisa-ação, voltada para a descrição de situações concretas e intervenção ou a ação orientada para resolução de problemas coletivos, no qual pesquisadores e participantes estão envolvidos (Thiollent, 1992). A pesquisa-ação é uma estratégia de investigação que visa compreender e intervir propositalmente ou intencionalmente na situação, com vista à modificá-la: "a pesquisa-ação propõe ao conjunto de sujeitos envolvidos mudanças que levem a um aprimoramento das práticas analisadas" (Severino, 2007, p.120). O método foi dividido em três fases:

Fase I: elaboração do diagnóstico da situação (levantamento dos fatores de risco e de proteção para a DPP);

Fase II: proposta de intervenção e implantação (grupo PNP);

Fase III: avaliação (rastreamento da DPP e avaliação do PNP).

Esta pesquisa contemplou as três fases da pesquisa-ação referidas, na qual foram identificados os fatores de risco e de proteção para a DPP e avaliado o material qualitativo e quantitativo colhido nas fases II e III. Este recorte diz respeito à avaliação do PNP especificamente direcionada as gestantes de alto risco usuárias da rede pública de saúde do Distrito Federal.

\section{Participantes}

A pesquisa contou com a participação de 10 mulheres captadas em um serviço de alto risco de um Hospital Público em Brasília entre os meses de agosto de 2012 e maio de 2013. Todas estavam gestantes e encontravam-se entre a $21^{\mathrm{a}}$ e $35^{\mathrm{a}}$ semanas de gestação, residiam no Distrito Federal ou entorno e possuíam o nível de escolaridade primário pelo menos (vide seção Resultados e discussão). As participantes foram divididas em dois grupos: Grupo A (mulheres que participaram do PNP) e Grupo B (mulheres que não participaram do PNP), caracterizando a amostra por conveniência.

Dentre os diagnósticos médicos que as levaram para o setor de alto risco encontram-se: rotura prematura de membranas ovulares, diabetes gestacional, hipertensão gestacional, trabalho de parto prematuro, infecção urinária, hepatite, pneumonia, gestação gemelar e oligodramnia (redução do líquido amniótico).

\section{Instrumentos}

Foram utilizados para a coleta de dados todos os instrumentos específicos para as fases I, II e II da pesquisa, a saber: 
Perfil gestacional: ficha elaborada pela equipe de pesquisa contendo dados sociodemográficos, histórico da gestação atual e/ou anterior e rede social de apoio, procurando identificar nestes dados os fatores de risco e de proteção para DPP. Aplicada nos dois grupos da pesquisa - Fase I.

Inventário Beck de Depressão-BDI (Beck, \& Steer, 1993): trata-se de uma escala composta por 21 itens com diferentes alternativas a respeito de como o sujeito tem se sentido recentemente, correspondendo a diferentes níveis de gravidade da depressão: mínimo, leve, moderado ou grave (Cunha, 2001). Aplicada nos dois grupos da pesquisa da Fase I.

Inventário Beck de Ansiedade-BAI (Beck, \& Steer, 1993): escala de autorrelato que mede a intensidade de sintomas de ansiedade. O inventário é constituído por 21 itens, que são afirmações descritivas de sintomas de ansiedade, e que devem ser avaliados pelo sujeito com referência a si mesmo, numa escala Likert de quatro pontos de "absolutamente não" a "gravemente: dificilmente pude suportar" (Cunha, 2001). Aplicada nos dois grupos da pesquisa da Fase I.

Sessões do PNP: Foram realizados quatro encontros de PNP e trabalhados temas como: as mudanças proporcionadas pela maternidade e paternidade; desmistificação da maternidade; o bebê imaginário $\mathrm{x}$ bebê real; gestação/puerpério $\mathrm{x}$ sexualidade; planos de parto; estados emocionais do pós-parto; cobranças sociais; vínculos mãe-bebê. Foi disponibilizado o espaço de escuta e utilizadas técnicas como recorte e colagem, leitura de textos sobre os temas abordados, vídeos, elaboração de desenhos por parte das participantes, dentre outras técnicas projetivas. As sessões foram gravadas para análise posterior das falas, percepções e vivências das colaboradoras - Fase II.

Perfil puerperal: ficha elaborada pela equipe de pesquisa contendo registros sobre o parto, o bebê e a amamentação, mudanças decorrentes do nascimento do bebê, estados emocionais nesse período, rede social de apoio e representação de ser mãe após o nascimento, a fim de identificar a percepção das puérperas sobre a qualidade do pós-parto. Aplicada nos dois grupos da pesquisa - Fase III.

Questionário avaliativo: composto por dez questões abertas e uma fechada, elaborado pela equipe de pesquisa para verificar a percepção das participantes do grupo PNP sobre os efeitos da sua participação nas sessões do PNP. Aplicado apenas ao grupo A - Fase III.
Escala COX: A Escala de Depressão Pós-Parto de Edimburgo (EPDS) (Cox, \& Holden, 2003), consiste em um instrumento bastante utilizado em estudos sobre DPP (Lobato et al., 2011) de autorregistro composto por dez enunciados, cujas opções são pontuadas (0 a 3) de acordo com a presença ou a intensidade do sintoma. Seus itens incluem sintomas como humor depressivo (sensação de tristeza, autodesvalorização e sentimento de culpa, ideias de morte ou suicídio), perda do prazer em atividades anteriormente consideradas agradáveis, fadiga, diminuição da capacidade de pensar, concentrar-se ou tomar decisões, sintomas fisiológicos (insônia ou hipersonia) e alterações do comportamento (crises de choro). A Escala considerada de sintomatologia depressiva apresenta valor igual ou superior a 12 (Ruschi et al, 2007). Aplicada nos dois grupos de pesquisa entre a quarta e oitava semana do pós-parto - Fase III.

\section{Procedimento de coleta de dados}

Após a aprovação no CEP/Fepesc, iniciou-se a coleta de dados. O projeto de pesquisa foi divulgado para as gestantes internadas no setor de alto risco da rede pública de saúde do Distrito Federal, bem como para os seus respectivos familiares presentes no horário de visita e para a equipe de saúde.

As gestantes foram convidadas a colaborar com a pesquisa de forma voluntária. Aquelas que aceitaram participar foram esclarecidas sobre os objetivos e metodologia do estudo por meio da assinatura do Termo de Consentimento Livre (TCLE) e responderam ao perfil gestacional e à Escala Beck para a realização da primeira fase da pesquisa-ação: o diagnóstico dos fatores de risco e proteção para DPP.

Após esta primeira fase, as 10 gestantes que concordaram em participar foram divididas em dois grupos: o grupo A, composto pelas cinco gestantes que participaram das sessões do PNP, e o grupo B, formado pelas cinco gestantes que não participaram das sessões de PNP. Posteriormente, iniciou-se a $2^{\text {a }}$ fase da pesquisa-ação: a implantação do PNP, no qual foram proferidas quatro sessões de aproximadamente 2 horas de duração cada, no período de quatro meses, sendo abordados temas sobre os aspectos psicológicos do ciclo gravídico-puerperal. Todas as sessões foram gravadas.

Por fim, foi realizada a $3^{\text {a }}$ fase da pesquisa-ação (avaliativa): à medida que os bebês foram nascendo, o perfil puerperal e a Escala COX foram aplicados 
para as participantes de ambos os grupos. O questionário avaliativo foi aplicado apenas às integrantes do primeiro grupo (A).

A aplicação desses instrumentos ocorreu por meio de visitas domiciliares agendadas com antecedência por contato telefônico ou no setor de alto risco do hospital.

\section{Procedimento para análise de dados}

Foi adotado como princípio a análise mista dos resultados. Primeiramente, foi realizada uma análise quantitativa, baseada em estatística simples dos perfis gestacional e puerperal. Posteriormente, uma análise quantitativa das Escalas Beck e COX, conforme seus respectivos manuais. Todas as sessões do grupo de PNP foram transcritas, organizadas e analisadas em seu conteúdo, em busca de fatores que não apareceram no primeiro instrumento aplicado (Bardin, 1977), sendo também realizada uma análise qualitativa dos questionários avaliativos do PNP e dos instrumentos aplicados nas visitas pós-parto (perfil puerperal, questionário avaliativo e Escala COX). Foram utilizados nomes fictícios para a análise e discussão de dados.

Depois da análise dos diversos materiais produzidos no desenvolvimento das fases da pesquisa (trechos de falas, comentários para as perguntas abertas nos perfis gestacional e puerperal e respostas do questionário avaliativo), foram identificados os fatores de risco e de proteção para DPP para cada colaboradora. Foi feita uma análise dos aspectos emocionais e psicológicos no período gestacional e comparados aos níveis de DPP presentes no puerpério, identificados pela escala COX e, a partir das características positivas e negativas, identificadas no pós-parto. Os dados foram sistematizados e apresentados em forma de tabelas e gráficos.

Por fim, foi realizado um comparativo entre os grupos A e B, com relação aos fatores de risco e de proteção durante a gestação e a incidência de DPP, com objetivo de avaliar o caráter preventivo do PNP, bem como verificar a satisfação das expectativas em relação ao atendimento realizado durante o pré-natal. Analisou-se ainda a percepção da vivência do pós-parto pelas colaboradoras da pesquisa.

\section{Resultados e discussão}

Caracterização das participantes: Foram incluídas no estudo 10 mulheres que se encontravam gestantes na $1^{\text {a }}$ e $2^{\text {a }}$ fase da pesquisa, e depois passaram a ser puérperas na $3^{a}$ fase do estudo. A idade das colaboradoras variou entre 19 e 38 anos (média $=27,5$ anos). São apresentados, inicialmente, os dados das participantes do PNP (Grupo A). Neste grupo, as idades gestacionais variaram de 21 a 33 semanas (na data em que preencheram o perfil gestacional) e a idade das gestantes incluídas variou entre 19 e 35 anos (média = 27,6 anos). Dentre essas, apenas duas eram casadas (40\%), enquanto três eram solteiras $(60 \%)$. Somente duas puérperas possuíam ensino superior (40\%); a maioria apresentava escolaridade média (60\%).

No grupo B, as idades gestacionais variaram de 20 a 34 semanas, e a idade das gestantes variou entre 20 e 38 anos (média $=27,8$ anos). Nenhuma colaboradora era casada, duas afirmaram estar em união estável (40\%) e três eram solteiras $(60 \%)$. Entre essas, duas possuíam ensino médio (40\%), enquanto a maioria tinha cursado apenas o ensino fundamental (60\%). Esses dados estão sintetizados na Figura 1.

A Figura 1 mostra que três mulheres do grupo A, que exerciam ocupação fora do lar, a maioria afirmou possuir um trabalho estressante (40\%), enquanto que, no grupo B, apenas uma colaboradora enquadrou-se nessa categoria (20\%). Quanto aos indicadores sociais, em ambos os grupos três gestantes afirmaram possuir renda familiar de até $\mathrm{R} \$ 1.000,00(60 \%)$, uma possui renda de até $\mathrm{R} \$ 540,00$ (20\%), e uma gestante afirmou possuir renda de até $\mathrm{R} \$ 2.000,00$ (20\%).

O número de gestações das puérperas do grupo A variou de uma à quatro ( $60 \%$ eram multíparas); uma afirmou a presença de depressão na gestação anterior (20\%) e duas na gestação atual (40\%); duas afirmaram terem tido um parto traumático/insatisfatório (40\%), uma teve história de aborto em gestação anterior (30\%) e apenas uma afirmou ter sofrido intercorrência hospitalar com o bebê (30\%). Quanto ao grupo B, 80\% das colaboradoras eram multíparas; duas afirmaram a presença de depressão na gestação anterior e durante a gestação atual (80\%); duas tiveram um parto traumático/insatisfatório (40\%) e outras duas tiveram história de aborto em gestação anterior e sofreram intercorrência hospitalar com o bebê (80\%). Esses dados podem ser confirmados na Figura 1, que apresenta as características sociodemográficas das colaboradoras e os fatores de risco e de proteção identificados na gestação (Figura 2). 


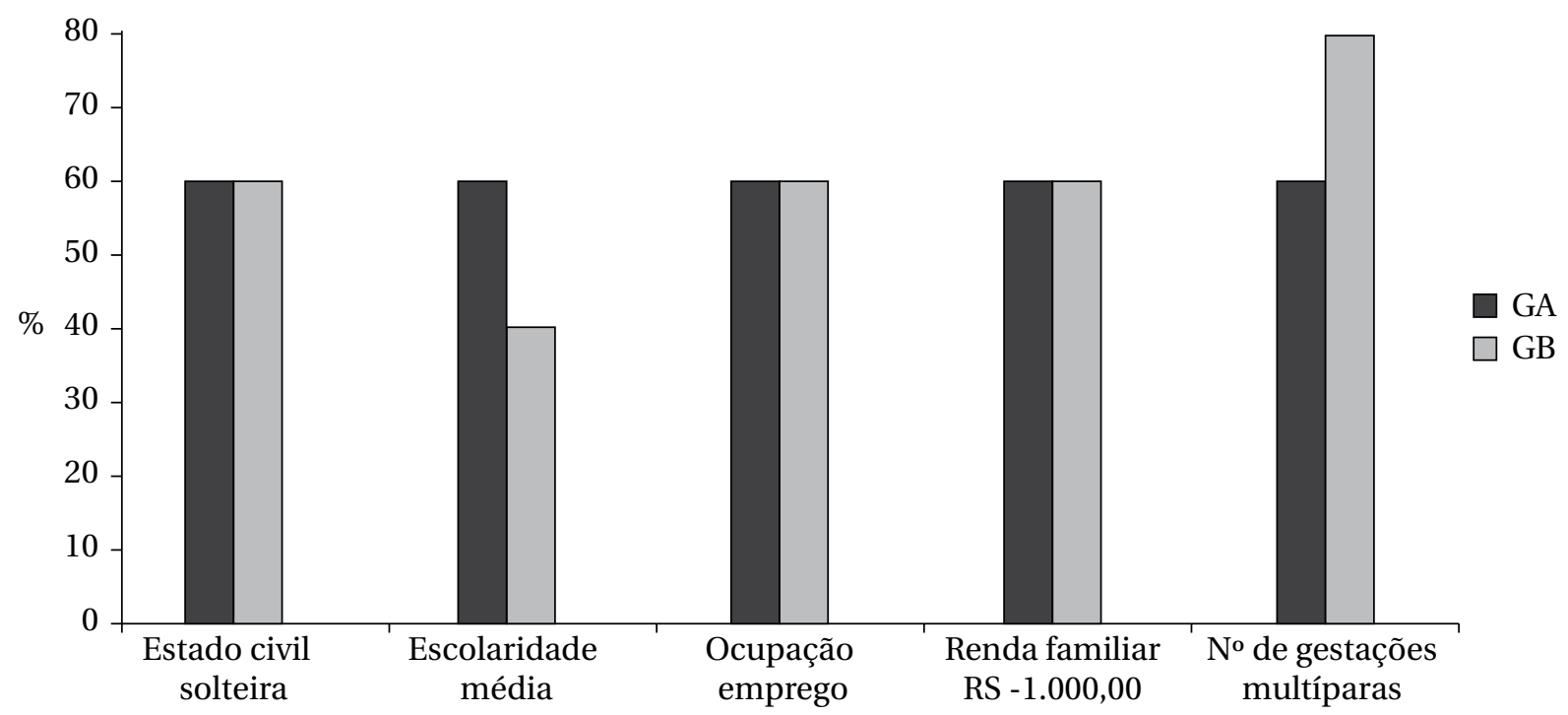

GA: idade: 19-35 anos (média $=27,6$ )

Idade gestacional: $21-33$ semanas (média $=28,6$ )
GB: idade $20-38$ anos (média $=27,8$ )

Idade gestacional: $20-34$ semanas (média $=29,4$ )

Figura 1

Características sócio-demográficas e histórico obstétrico das colaboradoras

A primeira fase da pesquisa foi diagnóstica visando identificar os fatores de risco e de proteção presentes na história e vivência das gestantes internadas no setor de alto risco. Conforme afirma Gomes et al. (2010), o conhecimento desses fatores é importante para o planejamento e execução de ações preventivas, como o favorecimento de apoio emocional à família, amigos e companheiro, proporcionando segurança à puérpera.

\section{Fatores de risco e proteção para a DPP}

Para melhor visualização dos dados, as Figuras 2 e 3 sintetizam e apresentam a ocorrência dos fatores de risco (Figura 2) e de proteção (Figura 3) mais frequentes para cada colaboradora participante dos grupos A e B.

Os fatores de risco encontrados foram: ser primípara; ser mãe solteira; gravidez não planejada; gravidez não desejada; saída da faculdade para o mercado de trabalho; trabalho estressante; desemprego; situação socioeconômica desfavorável; filhos saindo de casa; mudança de cidade/casa; rede de apoio social e familiar empobrecida; relacionamento conjugal insatisfatório; conflitos familiares; acidente de carro, moto ou ônibus; doença grave em parente próximo; morte de pessoa querida; falta de apoio do pai do bebê; história de depressão anterior; depressão gestacional; parto traumático ou insatisfatório; história de aborto em gestações anteriores e intercorrência hospitalar com a mãe.

Já os fatores de proteção evidenciados, também presentes nas pesquisas de Frizzo e Piccinini (2005), Arrais (2005) e Ruschi et al. (2007), foram: ser multípara; ser casada/relação estável; gravidez planejada; gravidez desejada; situação socioeconômica favorável; suporte familiar; relacionamento conjugal satisfatório; apoio emocional do pai do bebê; parto satisfatório e detecção precoce da DPP.

Pode-se observar nas Figuras 2 e 3 que a soma dos fatores de risco (46 ocorrências no grupo A e 44 no grupo B) e de proteção (18 ocorrências no primeiro grupo e 20 no grupo B) do grupo A quando comparados aos do grupo B apresentam índices semelhantes. Analisando-se apenas estes dados, pode-se afirmar que as colaboradoras de ambos os grupos encontravam-se vulneráveis, portanto com tendência a desenvolver a DPP.

Afim deinvestigarosfatores de risco mais frequentes em ambos os grupos, serão aqui discutidos os seguintes aspectos: escolaridade média, trabalho estressante, situação socioeconômica desfavorável, ser solteira; gravidez não planejada, relacionamento conjugal insatisfatório e falta de apoio emocional do pai do bebê. 
A maioria das colaboradoras possui nível baixo de escolaridade (30\% cursaram até o ensino fundamental e $50 \%$ até o ensino médio), são multíparas $(80 \%)$, apresentam situação socioeconômica desfavorável (70\%) e, entre as que exercem atividade laboral remunerada $(60 \%)$, quatro afirmaram possuir um trabalho estressante $(40 \%)$.
Essa amostra reflete a realidade da população brasileira, que em sua maioria é exposta à escassez de recursos. Um exemplo disso é o relato de P1: "Houve muita briga porque eu fiquei grávida, ele me culpou porque estamos passando por uma situação, por falta de dinheiro, e quase se separamos por causa disso".

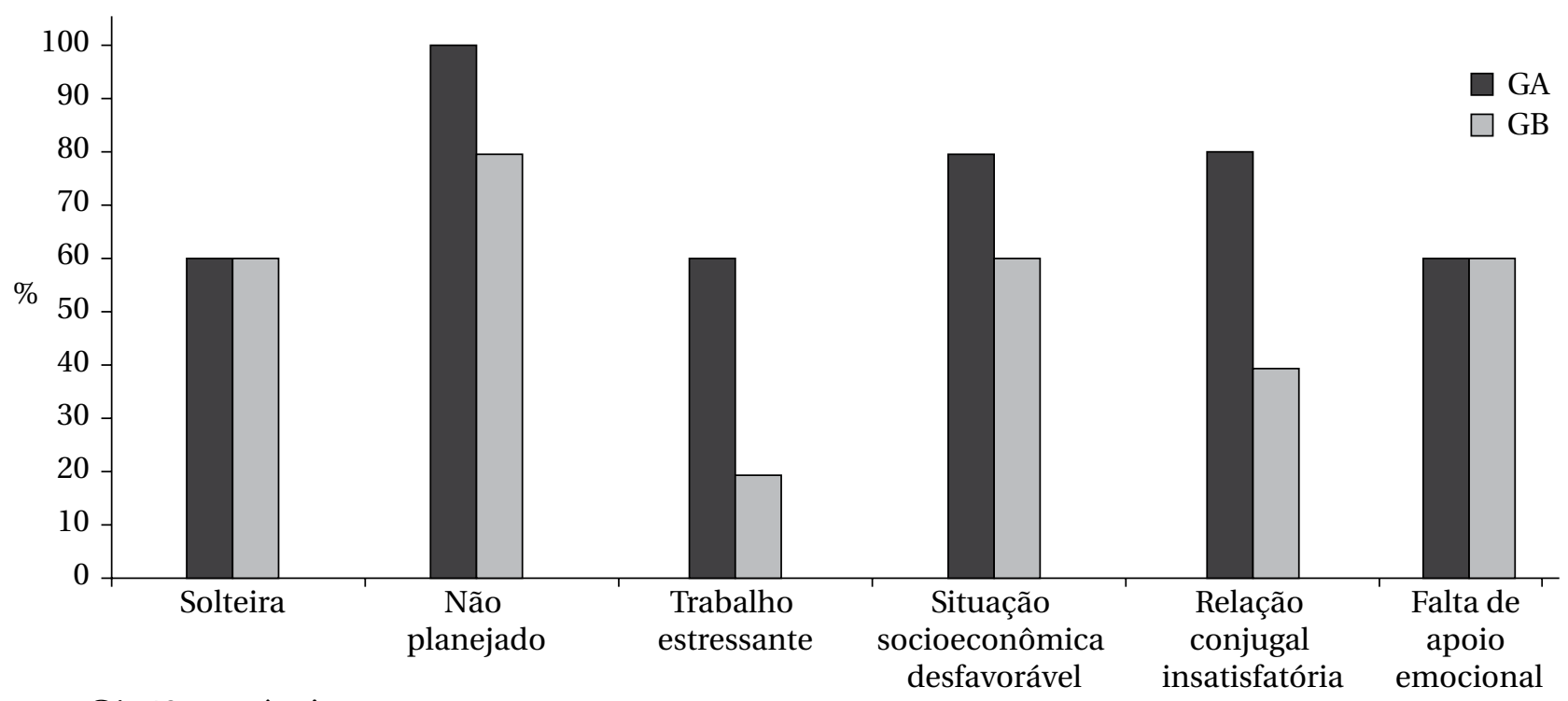

GA: 46 ocorrências

GB: 44 ocorrências

* GA/GB: Intercorrência hospitalar

Figura 2

Fatores de risco identificados na gestação das colaboradoras

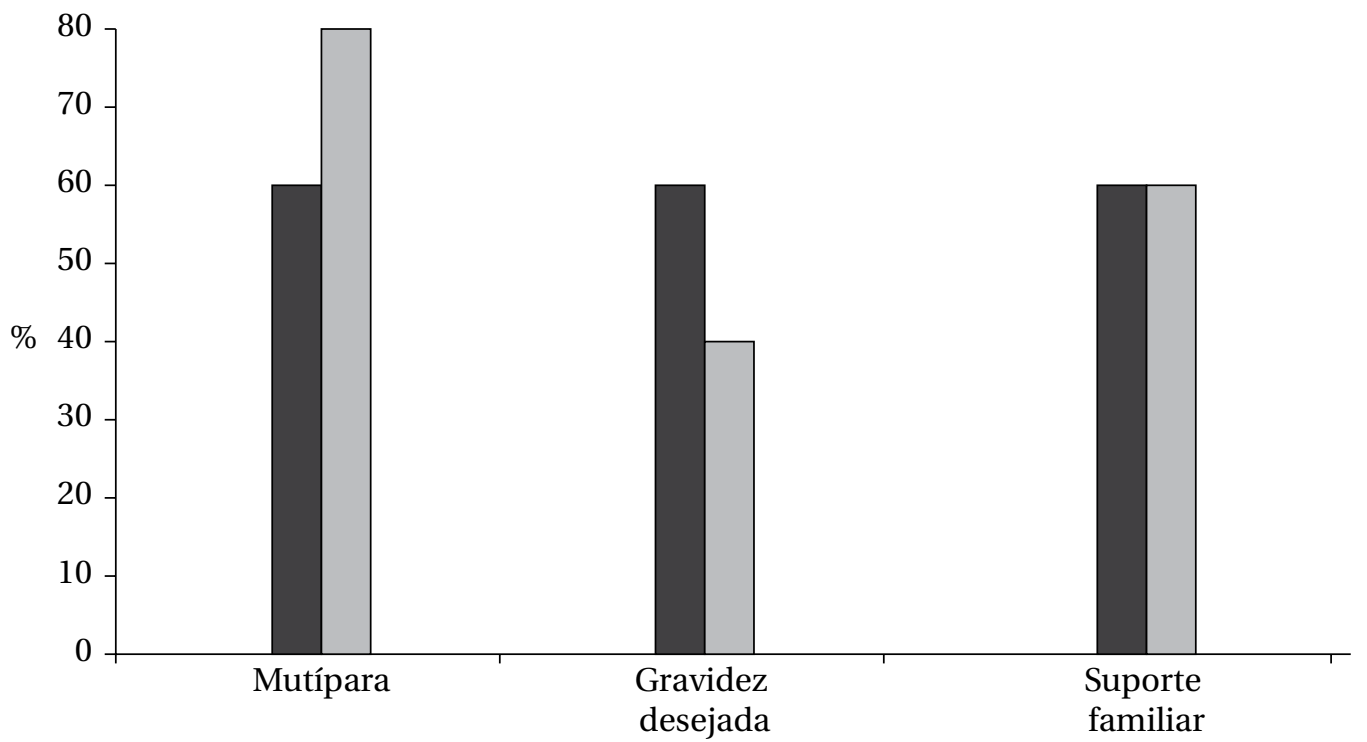

GA

$\square$ GB

GA: 18 ocorrências GB: 20 ocorrências

Figura 3

Fatores de proteção identificados na gestação das colaboradoras 
Em relação aos eventos estressantes, Silva e Piccinini (2009) afirmam que as mulheres que vivenciam tais situações possuem níveis maiores de sintomas depressivos, o que também foi relatado pelas colaboradoras da pesquisa: "Eu trabalhava de babá e saí de um emprego para outro pra estudar, e eu já estava grávida, só que eu não sabia, aí após eu entrar no outro emprego, descobriram que eu tava grávida e eles me mandaram embora" (P2). Dessa forma, conforme afirmam Higuti e Capocci (2003), Pereira e Lovisi (2008), e Viegas et al. (2008), a dificuldade financeira e a vivência de eventos estressantes pelas mulheres durante a gestação e o início do puerpério poderão desencadear a DPP.

Outros fatores de risco mencionados por Arrais (2005) eidentificados nos instrumentos desta pesquisa dizem respeito ao fato de a maioria das colaboradoras ser solteira, ao não planejamento da gravidez, ao relacionamento conjugal insatisfatório e à falta de apoio emocional do pai do bebê. O não planejamento da gravidez pode ser visualizado na seguinte fala:

"É, não foi planejada e eu não aceitei muito no início, e chorei muito quando fiquei sabendo [...] aí, assim, sabe aquele negócio de não querer mais? Sei lá se era raiva, aquela sensação ruim./ [...] eu fiquei triste por causa da situação da qual eu engravidei, sem um relacionamento concreto, sem uma estabilidade como falam [...] a gente tava só começando, foi um relacionamento que não deu certo" (P3).

A fala anterior corrobora a afirmação de Moraes et al. (2006), que cita fatores como a não aceitação da gravidez, bem como a falta de suporte oferecido pelo companheiro e a sobrecarga de trabalho (ser mãe solteira), associados à ocorrência de DPP. Conforme menciona Maushart (2006), esses fatores relacionam-se à DPP, uma vez que as mães da nossa sociedade vivem na tentativa de reconciliar as expectativas com as realidades práticas.

Em decorrência desta situação, o fato do evento não ter sido planejado contribui para que elas assumam a total responsabilidade pelas exaustivas tarefas diárias associadas aos cuidados domésticos e com os seus filhos. Dessa forma, a cobrança e a exigência para que a mulher consiga desempenhar perfeitamente todas as suas atividades propiciam o surgimento do conflito entre o que é certo e errado:
"O descompasso entre as expectativas e as realidades da maternidade pode ser vivido como uma crise pessoal, mas, em última instância, é uma tragédia social" (Maushart 2006, p. 157).

Esses resultados sugerem que, além da presença dos fatores de risco apresentados pelas gestantes, o fato de terem vivenciado dificuldades gestacionais relacionadas a sua saúde e/ou do bebê, determinando a internação no setor de alto risco, contribui significativamente para a instalação de um possível quadro de depressão tanto durante quanto após a gestação. Assim, os profissionais que trabalham com essas gestantes deverão estar atentos às várias condições de risco que estão associadas a essas mulheres, pois poderão atuar de forma preventiva na diminuição dos riscos gestacionais (Baptista, \& Furquim, 2009).

Em função da relevância como fator de risco para DPP, destacaremos os resultados referentes aos níveis de depressão gestacional e rastreamento de depressão pós-parto nos dois grupos (Figura 4).

É interessante observar que no grupo A apenas duas colaboradoras $(40 \%)$ apresentaram nível de ansiedade grave (P3 e P4), sendo que do total da amostra, somente uma (20\%) apresentou nível de depressão gestacional grave (P3), de acordo com a escala Beck. No grupo B, a maioria apresentou nível de ansiedade gestacional grave $(80 \%)$, sendo que duas (40\%) apresentaram nível de depressão gestacional grave (P8 e P10) e uma (20\%) apresentou nível moderado (P7).

Importante lembrar ainda que, no grupo A, uma colaboradora (20\%) afirmou histórico de depressão anterior (P5) e duas (40\%) mencionaram a presença de depressão na gestação (P3 e P5), enquanto que, no grupo B, duas apresentaram histórico de depressão anterior (40\%) e durante a gestação (P8 e P10). Esses dados confirmam a afirmação de Arrais (2005); Pereira e Lovisi (2008); Rosenberg (2007); Schmidt, Piccoloto e Muller (2005), e Zinga et al. (2012), na qual a presença de depressão na gestação representa um dos grandes fatores de risco para a DPP.

De acordo com os dados obtidos, pode-se afirmar que, apesar de as colaboradoras de ambos os grupos serem vulneráveis e com tendência a desenvolver a DPP, nenhuma das gestantes que participaram do PNP - Grupo A - desenvolveram DPP, enquanto que as cinco puérperas do grupo $\mathrm{B}$, que não participaram do PNP, evidenciaram probabilidade para a DPP (Figura 4). 


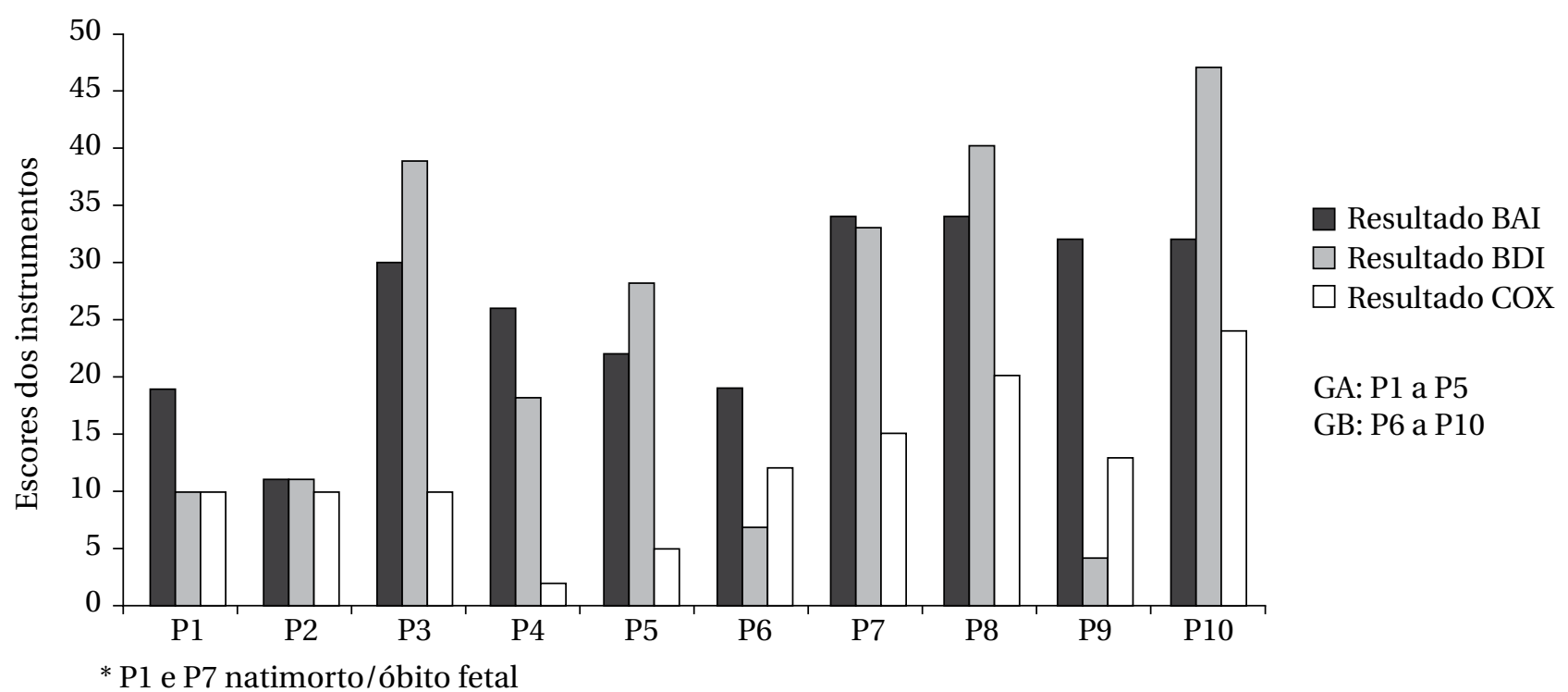

Figura 4

Níveis de depressão gestacional e depressão pós-parto nos grupos A e B

Outra questão que merece destaque é o fato de que os bebês de duas participantes da pesquisa evoluíram para óbito - uma do grupo A (P1 - natimorto) e outra do grupo B (P7 - óbito fetal) - o que representa um fator de risco para a DPP. Tendo em vista que ambas as colaboradoras apresentavam fatores de risco semelhantes na fase diagnóstica da pesquisa (gravidez não planejada, situação socioeconômica desfavorável e relacionamento conjugal insatisfatório) e que somente a colaboradora do grupo B apresentou probabilidade para DPP, segundo a escala COX, cabe questionar se a participação de P1 no PNP permitiu que, de alguma forma, a depressão fosse tratada ou minimizada.

Quanto aos fatores de proteção mais frequentes em ambos os grupos, destacam-se: ser multípara $(80 \%)$, gravidez desejada $(50 \%)$ e suporte familiar (60\%), conforme as seguintes falas:

Descobrir a gravidez foi bom, eu não fiquei triste, eu fiquei muito feliz, não foi planejada, mas assim, a gente não se preveniu e sabia que qualquer hora poderia acontecer. Mesmo assim, nem ficamos chateados com o que aconteceu (P2).

O Caio foi uma surpresa pra todo mundo, mas é muito desejado. Está todo mundo ansioso pra ver o rostinho dele. [...] a minha família e a dele ajuda bastante, minha mãe, minha avó, minha cunhada e minha sogra, ela é um amor de pessoa. (P6).
Conteúdo semelhante ao da fala de P6 foi mencionado por autores como Cantilino, Zambaldi, Sougey e /rennó Junior (2010); Frizzo e Piccinini (2005), e Konradt et al. (2011), ao afirmarem a importância do suporte social adequado como um fator protetor para o desenvolvimento de DPP.

Avaliação do PNP: Na última fase da pesquisa (avaliativa), os dados provenientes do perfil puerperal, do questionário avaliativo e das sessões iniciais do PNP demonstraram a influência positiva do PNP para cada colaboradora do grupo-intervenção, na medida em que elas fizeram a avaliação de todo o trabalho desenvolvido e refletiram sobre o que aprenderam; os mitos desfeitos e o apoio recebido, possibilitando a revisão da máscara da maternidade (Maushart, 2006). Essa influência positiva pode ser visualizada nas seguintes falas: "Aqui vocês puderam me ajudar, me aconselhar. Se não fosse vocês eu acho que não teria dado conta só. Nos momentos bem difíceis da minha vida me ajudou sim, bastante mesmo" (P3); "Durante a gestação se eu tivesse passado aqui sozinha, sem o apoio de vocês, sem alguém pra conversar, me acalmar, me ajudar, eu não tinha conseguido" (P5). De acordo com as participantes, o grupo do PNP também proporcionou a reflexão e a discussão sobre o conceito de ser mãe: "É responsabilidade, compromisso, dedicação e muito amor no coração" (P1); "É maravilhoso, a gente aprende a amar no ventre da gente, a esquecer dos problemas. É muito bom! É um sonho. A mais alta dádiva de Deus” (P5). 
Observa-se nas falas acima a idealização da maternidade, na qual, de acordo com Azevedo e Arrais (2006), espera-se um ideal, um modelo de mãe perfeita, uma imagem romanceada da maternidade, que está alicerçada sob um rígido padrão incapaz de admitir qualquer vestígio de sentimentos ambivalentes nas mães. Por outro lado, no decorrer dos encontros grupais, observou-se mudanças no conceito e na maneira de lidar com a maternidade: "[...] eu como mãe vou errar, mas na medida do possível vou tentar acertar e fazê-lo feliz, essa felicidade que faz todas nós mães se emocionar, a amar incondicionalmente, ou seja, desabrochar para o falado amor" (P1).

Outras mudanças também puderam ser percebidas em relação à melhoria da qualidade do relacionamento com o pai do bebê, ao conceito de parto e amamentação e a melhoria dos possíveis sintomas da DPP: "O pai do bebê está dando mais atenção para ela, carinho, e eu estou tendo dificuldade para administrar dois filhos" (P3); "O parto normal além de ser só um corte lá embaixo quando precisa, acredito que depois a dor passa" (P1); "A amamentação é importante, é fundamental para o bebê até os seis meses de idade, porque quando a criança mama ela não precisa de água e de nada, é algo suficiente pra ela" (P1); "Por mais difícil que a gente ache que seja o problema, vai ser resolvido, tudo passa. É como se fosse uma ferida, por mais que dói ela é curada, vai cicatrizar e passar" (P2).

Por fim, o grupo de PNP vai além do objetivo geral deste trabalho, por ser um instrumento psicoeducativo e por abordar questões sobre o projeto de maternidade/parentalidade, questões diárias, culturais, geracionais, relacionadas à internação, aos medos e preocupações, propiciando o empoderamento das participantes e o fortalecimento da rede social.

Vivência puerperal: Em relação ao puerpério, pode-se observar na Figura 5 que todas as puérperas que preencheram o perfil puerperal (P2, P3, P4, P5, P6, $\mathrm{P} 8, \mathrm{P9}, \mathrm{P} 10)$ desejavam que seu parto fosse normal e afirmaram preferir a presença de um acompanhante, entretanto, o parto cesáreo foi realizado na maioria das gestantes $(60 \%)$, exceto em P4 e P6. Isso pode ser explicado pelo fato de as gestantes serem consideradas de alto risco e apresentarem maior probabilidade de evolução desfavorável durante a gestação (Brasil, 2012).

Todas as puérperas do grupo A afirmaram que o parto ocorreu conforme o esperado, enquanto que, no grupo B, apenas uma participante teve a mesma opinião (P9). Pode-se concluir que, apesar de o tipo de parto desejado pelas participantes do grupo A não ter sido realizado, elas se sentiram mais tranquilas porque receberam informações no grupo PNP pertinentes à temática, preparando-as para o parto e pós-parto, independente de suas expectativas iniciais. A tranquilidade sentida pelas colaboradoras em relação ao tipo de parto realizado foi expressa nas seguintes falas: "Não tive medo, foi maravilhoso!" (P2); “Eu tive cesárea por causa da saúde dela, mais eu me senti preparada com as informações que recebi de vocês" (P3); "Foi supertranquilo. Os médicos foram maravilhosos, me atenderam super bem, e a anestesia, que eu tinha mais medo, foi bem tranquila, vocês me acalmaram muito no dia anterior" (P5).

Outro aspecto que merece destaque é o fato que de duas puérperas do grupo A (P3 e P5) apresentaram dificuldades relacionadas à amamentação, enquanto que o mesmo não ocorreu entre as participantes do grupo B. Apesar desses resultados, pode-se afirmar que as puérperas do grupo A receberam todas as informações necessárias relacionadas à amamentação durante o grupo PNP, o que as ajudou a lidar de maneira positiva com as dificuldades apresentadas.

Por fim, todas as participantes do grupo A que apresentaram os mesmos fatores de risco para a DPP que as colaboradoras do grupo B (situação socioeconômica desfavorável; rede de apoio social e familiar empobrecida; relacionamento conjugal insatisfatório; conflitos familiares) afirmaram possuir, no pós-parto, o apoio emocional e financeiro, e mencionaram contar com ajuda de seus familiares e amigos nos cuidados com o bebê, confirmando a eficácia do grupo PNP na melhoria dos relacionamentos/rede de apoio. Dessa forma, os resultados discutidos nesta seção sugerem que o PNP atuou como fator de proteção para a prevenção da DPP nas gestantes que participaram do grupo de PNP, reforçando o caráter psicoprofilático deste tipo de trabalho conforme apontado por Arrais et al. (2012); Bortoletti (2007a,b); Santos (2013) e Shields (2006).

Assim sendo, pode-se concluir que o grupo de PNP, além da abordagem psicoterapêutica, forneceu informações sobre os estados emocionais do pós-parto, favorecendo a adaptação das puérperas neste período, proporcionando o fortalecimento do vínculo entre mãe-concepto (Falcone, Mäder, Nascimento, Santos, \& Nóbrega, 2005). 


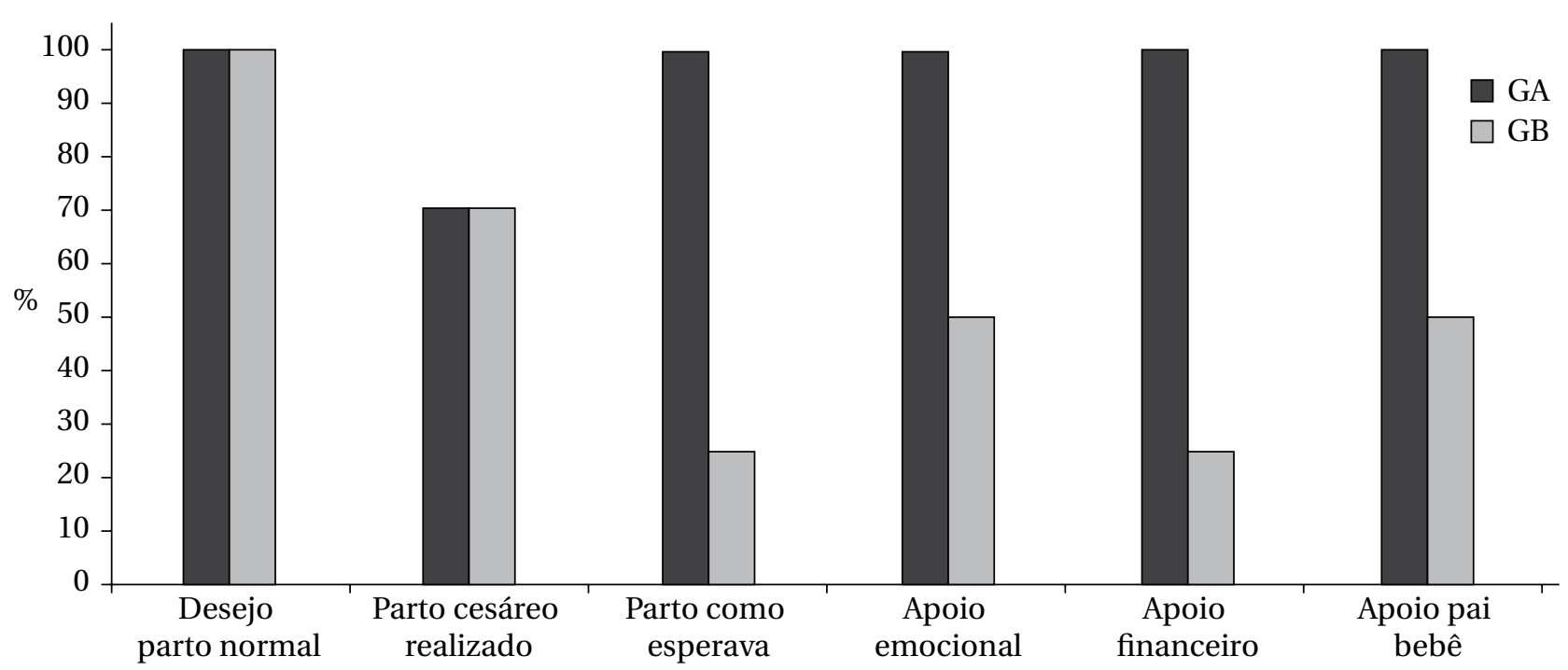

* P1 e P7 não responderam perfil puerperal (natimorto/óbito fetal)

Figura 5

Características pós-parto (Perfil puerperal)

\section{Considerações finais}

Considerando-se o objetivo geral desta pesquisa: investigar a eficácia do PNP na prevenção à DPP em gestantes de alto risco de um hospital público de referência, em Brasília; verifica-se que a realização do PNP atuou de forma positiva na prevenção da DPP em gestantes de alto risco, já que as cinco colaboradoras do PNP não apresentaram probabilidade para a DPP, mesmo com a presença de fatores de risco durante a gestação.

Alguns fatores de risco citados pelas colaboradoras da pesquisa e que contribuíram para a DPP incluem: privação de sono, complicações na gravidez, complicações no nascimento para a mãe ou para o filho, apoio social inadequado, problemas matrimoniais, histórico de depressão, e a ocorrência recente de uma grande mudança de vida (divórcio, morte, um novo emprego, mudança de cidade).

A pesquisa-ação mostrou-se adequada e eficaz para o objetivo proposto, tendo em vista que a comparação entre os dois grupos - colaboradoras participantes do PNP e as não participantes - foi fundamental para percebemos a proteção que o PNP oferece durante a gestação. Embora esses achados não possam ser interpretados de forma isolada de outros aspectos de vida da gestante, defendemos que o PNP, associado a outros fatores de proteção presentes na história das grávidas, pode ajudar a prevenir a DPP. Assim, destacamos o grupo de PNP como um fator de proteção a mais na vida das gestantes, na medida em que proporciona às puérperas um espaço de escuta emocional e apoio, onde o tema da DPP pode ser adequadamente abordado, permitindo a livre expressão de seus temores e ansiedades.

É sob esse aspecto que mais se aprofunda o valor terapêutico do grupo, na medida em que permite o manejo de sentimentos básicos em relação à maternidade, tais como níveis de insegurança, sentimentos de inferioridade e inadequação e expectativas referentes ao bebê e a si próprias como mãe. Portanto nossos resultados corroboram a afirmação de Campos (2000):

A realização de acompanhamento psicológico durante a gravidez em mulheres de risco, pode contribuir para uma vivência mais saudável desse período maturacional, prevenindo perturbações no processo de desenvolvimento gravídico e consequentes ocorrências patológicas, como complicações no parto e distúrbios emocionais no pós-parto, ou ainda, e de forma mais negativa, o parto prematuro (Campos, 2000, p. 31).

Vale ressaltar que todas as colaboradoras da pesquisa foram convidadas a ingressar no grupo de PNP, porém, vários motivos impediram algumas delas de participar: falta de desejo/ motivação, alta hospitalar, falta de recursos financeiros para retornar ao hospital, choque de horário com outras rotinas hospitalares (exames, visitas, lanche). Desta forma, foi possível constituir o Grupo B citado na pesquisa. 
Entretanto, estas colaboradoras foram contatadas no período pós-parto e algumas foram acompanhadas pelo serviço de psiquiatria, Psicologia e serviço social do setor, até mesmo receberam enxovais doados pela equipe de pesquisa, na ocasião da visita pós-parto. Assim, a assistência psicológica na gestação por meio da utilização do PNP é importante instrumento psicoprofilático, reafirmando a concepção de Bortoletti (2007); Cabral et al. (2012), que cita o PNP como um fator de proteção por si só, minimizando o impacto dos fatores de risco presentes e diminuindo dessa forma a possibilidade da DPP.

É preciso destacar também a necessidade de uma equipe interdisciplinar para auxiliar a gestante, visando à investigação de todos os fatores de risco que podem ocasionar transtornos físicos ou psicológicos ao binômio mãe x bebê, incentivando a criação de um espaço que possibilite relações humanas mais saudáveis entre os membros da equipe e entre a equipe e o paciente. Embora a atuação do psicólogo hospitalar aplicada à obstetrícia possa parecer prescindível, se comparada à equipe médica e de enfermagem, os resultados de sua atuação têm demonstrado o seu valor, diante da gama de situações vivenciadas pelas usuárias em seus contextos individuais e subjetivos, revelando a complexidade do atendimento à gestante, visando o seu bem-estar e o do bebê.

No centro obstétrico, a Psicologia trabalha com multifatores e o seu campo de atuação não fica restrito à supervisão de partos e ao manejo da dor durante o trabalho de parto, pois abrange aspectos biopsicossociais das usuárias, através de mediações entre a equipe multidisciplinar e os familiares, bem como ressaltando a importância do grupo de PNP.

Os objetivos deste trabalho foram além dos estabelecidos incialmente, por toda a estrutura do serviço de referência, desenvolvidos para oferecer conforto

\section{Referências}

Alt, M. S., \& Benetti, S.P.C. (2008). Maternidade e depressão: impacto na trajetória de desenvolvimento. Psicologia em Estudo, 13(2), 389-394. doi:10.1590/S1413-73722008000200022

American Psichyatric Association. (2002). Мanual diagnóstico e estatístico de transtornos mentais: $D S M-I V-T R$ (4a ed.). Porto Alegre, RS: Artmed. e bem-estar às gestantes e seus familiares, visando à promoção, prevenção e assistência integral à saúde da gestante e do recém-nascido. Dessa forma, o psicólogo hospitalar assume um papel fundamental nesse contexto, pois, conforme afirmam Baptista e Furquim (2009), Iaconelli (2005), o apoio psicológico em um momento de tantas mudanças externas e internas pode contribuir com a equipe multidisciplinar na melhor adaptação da mulher, desde a gestação até a chegada do bebê.

Por fim, sabendo-se da alta incidência de DPP e, após as evidências do caráter preventivo do PNP proposto neste trabalho, a continuidade de estudos dessa ordem é de grande importância e se faz necessária para o entendimento dos fatores intervenientes na depressão puerperal, e para a compreensão dos efeitos de risco da DPP sobre aspectos da vida do bebê.

Este trabalho possibilitou enorme crescimento pessoal e profissional na área da Psicologia Hospitalar aplicada à obstetrícia, primeiramente por contribuir com a ampliação do conhecimento sobre as diversas facetas que envolvem o tema da maternidade e depressão pós-parto, e por realçar a importância do psicólogo no contexto do atendimento pré-natal, já que a DPP é importante problema de saúde pública, que impacta diretamente sobre a saúde da mãe e do bebê, e ainda subdiagnosticada, atingindo mulheres em todas as idades, classes sociais e níveis de escolaridade.

Um estudo futuro, com um número maior de participantes, a aplicação da escala de autoeficácia materna no pós-parto (Uchoa, 2012) e a ampliação da assistência pré-natal oferecida nos serviços públicos de saúde, também poderia ajudar a ratificar que o PNP atua como fator de proteção para DPP, justificando a relevância social e científica do presente estudo.

Arrais, A. R. (2005). As configurações subjetivas da depressão pós-parto: para além da padronização patologizante (Tese de doutorado). Instituto de Psicologia, Universidade de Brasília, Brasília, DF.

Arrais, A. R., Cabral, D. S. R., \& Martins, M. H. F. (2012). Grupo de pré-natal psicológico: avaliação de programa de intervenção junto a gestantes. Encontro: Revista de Psicologia, 15(22), 53-76. 
Arrais, A. R., Mourão, M. A., \& Fragalle, B. (2014). Opré-natal psicológicocomo programa de prevenção a depressão pós-parto. Saúdee Sociedade, 23(1), 251-264. doi:10.1590/S0104-12902014000100020

Azevedo, K. R., \& Arrais, A. R. (2006). O mito da mãe exclusiva e seu impacto na depressão pós-parto. Psicologia: Reflexão e Crítica, 19(2), 269-76. doi:10.1590/S0102-79722006000200013

Baptista, A. S. D., \& Furquim, P. M. (2009). Enfermaria de obstetrícia. In: M. N. Baptista, \& R. R. Dias, Psicologia hospitalar: teoria, aplicações e casos clínicos (pp. 12-31). Rio de Janeiro, RJ: Guanabara Koogan.

Bardin, L. (1977). L'analyse du contenu. Paris: PUF.

Beck, A. T., \& Steer, R. A. (1993). Beck depression inventory manual. San Antonio: Psychology Corporation. Bortoletti, F. F. (2007b). Psicodinâmica do ciclo gravídico puerperal. In: A. F. Moron, F. F. Bortoletti, J. Bortoletti Filho, M. U. Nakamura, R. M. Santana, \& R. Mattar. Psicologia na prática obstétrica: abordagem Interdisciplinar (pp. 21-31). Barueri, SP: Manole.

Bortoletti, F. F. (2007a). Psicoprofilaxia no ciclo gravídico puerperal. In: A. F. Moron, F. F. Bortoletti, J. Bortoletti Filho, M. U. Nakamura, R. M. Santana, \& R. Mattar. Psicologia na prática obstétrica: abordagem Interdisciplinar (pp. 37-46). Barueri, SP: Manole.

Brasil. Ministério da Saúde. (2001). Área Técnica de Saúde da Mulher. Parto, aborto e puerpério: assistência humanizada à mulher. Brasília, DF: o autor.

Brasil. Ministério da Saúde. (2006). Área Técnica de Saúde da Mulher. Pré-natal e puerpério: atenção qualificada e humanizada. Brasília, DF: o autor.

Brasil. Ministério da Saúde. (2012). Secretaria de Atenção à Saúde. Gestação de alto risco: manual técnico. Brasília, DF: o autor.

Campos, R. C. (2000). Processo gravídico, parto e prematuridade: Uma discussão teórica do ponto de vista do psicólogo. Análise Psicológica, 18(1), 15-35. doi:10.14417/ap.419

Cantilino, A., Zambaldi, C. F., Sougey E. B., Rennó Junior, J. (2010). Postpartum psychiatric disorders. Revista Psiquiatria Clínica, 7(6), 278-284. doi:10.1590/S0101-60832010000600006

Chiattone, H. B. C. (2007). Assistência psicológica de urgência. In: A. F. Moron, F. F. Bortoletti, J. Bortoletti Filho, R. M. Santana, \& R. Mattar. Psicologia na prática obstétrica: abordagem Interdisciplinar (pp. 52-59). Barueri, SP: Manole.
Cox, J., \& Holden J. (2003). Perinatal mental health: a guide to the Edinburgh Postnatal Depression Scale (EPDS). London: Royal College of Psychiatrists.

Cunha, J. (2001). Manual em português das Escalas Beck. São Paulo: Casa do Psicólogo.

Falcone, V. M., Mäder, C. V. N., Nascimento C. F. L, Santos J. M. M., \& Nóbrega F. J. (2005). Atuação multiprofissional e a saúde mental de gestantes. Revista de Saúde Pública, 39(4), 612-618. doi:10.1590/S0034-89102005000400015

Frizzo, G. B., \& Piccinini, C. A. (2005). Interação mãe-bebê em contexto de depressão materna: aspectos teóricos e empíricos. Psicologia em Estudo, 10(1), 47-55. doi:10.1590/S1413-73722005000100007

Gomes, L. A., Torquato, V. S., Feitoza A. V., Souza, A R., Silva M. A. M, Pontes, R. J. S. (2010). Identificação dos fatores de risco para depressão pós-parto: Importância do diagnóstico precoce. Revista da Rede de Enfermagem do Nordeste, 11(4), 117-123. Recuperado de http://www.redalyc.org/ articulo.oa?id=324027973013

Higuti, P. C. L., \& Capocci, P.O. (2003). Depressão pós-parto. Revista de Enfermagem Unisa, 4, 46-50. Recuperado de http://www.unisa.br/graduacao/ biologicas/enfer/revista/arquivos/2003-11.pdf

Iaconelli, V. (2005). Depressão pós-parto, psicose pós-parto e tristeza materna. Revista Pediatria Moderna, 41(4). Recuperado de http://www.institutogerar.com.br/artigos/24_ARTIGO_\%20DPP,\%20 PSICOSE\%20P\%C3\%93S\%20PARTO\%20E\%20TRISTEZA\%20MATERNA.pdf

Klein, M. M. S., \& Guedes, C. R. (2008). Intervenção psicológica a gestantes: contribuições do grupo de suporte para a promoção da saúde. Psicologia Ciência e Profissão, 28(4), 862-871. doi:10.1590/S1414-98932008000400016

Konradt, C. E., Silva R. A., Jansen, K., Vianna, D. M., Quevedo, L. A., Souza, L. D. M. et al. (2011). Depressão pós-parto e percepção de suporte social durante a gestação. Revista de Psiquiatria Rio Grande do Sul, 33(2), 76-79. doi:10.1590/S0101-81082011005000010

Lobato, G., Moraes, C. L., \& Reichenheim, M. E. (2011). Magnitude da depressão pós-parto no Brasil: uma revisão sistemática. Revista Brasileira de Saúde Materno-Infantil, 11(4), 369-379. doi:10.1590/S1519-38292011000400003 
Maushart, S. (2006). A máscara da maternidade: por que fingimos que ser mãe não muda nada. São Paulo, SP: Melhoramentos.

Moraes, I. G. S., Pinheiro, T.T., Silva R.A., Horta B.L., Sousa, P. L. R., Faria,A.D. (2006). Prevalência da depressão pós-parto e fatores associados. Revista de Saúde Pública, 40(1), 65-70. doi:10.1590/S0034-89102006000100011

Oliveira, M. A., \& Nakano, T. C. (2011). Revisão de pesquisas sobre criatividade e resiliência. Temas em Psicologia, 19(2), 467-479. Recuperado de http:// pepsic.bvsalud.org/scielo.php?script=sci_arttext\&pid=S1413-389X2011000200010

Pereira, P. K., \& Lovisi, G. M. (2008). Prevalência da depressão gestacional e fatores associados. Revista de Psiquiatria Clínica, 35(4), 214-220. doi:10.1590/S0101-60832008000400004

Ramos, S. H. A. S., \& Furtado, E. F. (2007). Depressão puerperal e interação mãe-bebê: um estudo piloto. Psicologia em Pesquisa, 1(1), 20-28. Recuperado de http:// pepsic.bvsalud.org/scielo.php?script=sci_ arttext\&pid=S1982-12472007000100005

Rios, C. T. F., \& Vieira, N. F. C. (2007). Ações educativas no pré-natal: reflexão sobre a consulta de enfermagem como um espaço para educação em saúde. Ciência e Saúde Coletiva, 12(2), 477-486. doi:10.1590/S1413-81232007000200024

Rosenberg, J. L. (2007). Transtornos psíquicos da puerperalidade. In: F. F. Bortoletti et al., Psicologia na prática obstétrica: abordagem Interdisciplinar (pp. 110-117). Barueri, SP: Manole.

Ruschi, G. E. C., Sun, S. Y., Mattar, R., Chambô Filho, A., Zandonade,E, \&Lima,V.J. (2007).Aspectosepidemiológicos da depressão pós-parto em amostra brasileira. Revista de Psiquiatria do Rio Grande do Sul, 29(3), 274-280. doi:10.1590/S0101-81082007000300006

Santos, M. F. S. (2001). Depressão após o parto (Tese de doutorado). Instituto de Psicologia, Universidade de Brasília, Brasília, DF.

Santos, S. R. M. L. (2013). Menina, mulher, filha, mãe? A gravidez decorrente da violência sexual (Tese de doutorado). Instituto de Psicologia, Universidade de Brasília, Brasília, DF.

Schmidt, E. B., Piccoloto, M. N.,\& Muller, M. C. (2005). Depressão pós-parto: fatores de risco e repercussões no desenvolvimento infantil. Psico- USF, 10(1), 61-68. Recuperado de http://www.scielo.br/ pdf/pusf/v10n1/v10nla08.pdf
Severino, A. J. (2007). Metodologia do trabalho científico. São Paulo, SP: Cortez.

Shields, B. (2006). Depois do parto, a dor: minha experiência com a depressão pós-parto. São Paulo, SP: Prestígio.

Silva, M. R., \& Piccinini, C. A. (2009). Paternidade no contexto da depressão pós-parto materna: revisando a literatura. Estudos de Psicologia (Natal), 14(1), 5-12. doi:10.1590/S1413-294X2009000100002

Thiollent, M. (1992). Metodologia da pesquisa-ação. São Paulo, SP: Cortez.

Uchoa, J. L. (2012). Autoeficácia das mulheres no ciclo gravídico-puerperal em amamentar (Dissertação de mestrado) Faculdade de Farmácia, Universidade Federal do Ceará, Fortaleza, CE.

Viegas, L. M., Silva, G. A., Cecchini, M., Felipe, R., Otta, E., \& Bussab, V. S. R. (2008). Depressão pós-parto, histórico reprodutivo materno e apoio social. Bis: Boletim do Instituto de Saude, (46), 1-49. Recuperado de http:// periodicos.ses.sp.bvs.br/pdf/bis/n46/n46a04.pdf

Yamaguchi, L. M., Pita, J. C. N., \& Martins, L. A. N. (2007). A paciente psiquiátrica no ciclo gravídico puerperal. In A. F. Moron, F. F. Bortoletti, J. Bortoletti Filho, M. U. Nakamura, R. M. Santana, \& R. Mattar, Psicologia na prática obstétrica: abordagem interdisciplinar (pp. 118-121). Barueri, SP: Manole.

Zinga, D., Phillips, S. D., \& Born, L. (2012). Depressão pós-parto: sabemos os riscos, mas podemos preveni-la? Revista Brasileira em Psiquiatria, 27(2), 56-64. doi:10.1590/S1516-44462005000600005

\section{Natália Maria de Castro Almeida}

Especialista pelo Hospital das Clínicas da Universidade de São Paulo - USP, São Paulo - SP. Brasil. Psicóloga clínica e hospitalar do Hospital Brasília - DF.

E-mail: Almeida.nataliamc@gmail.com

Endereço para envio de correspondência: SQSW - Quadra 300 Bloco G apartamento 206. Sudoeste - Brasília - DF - CEP 70.673.034

\section{Alessandra da Rocha Arrais}

Doutora e Pós-doutora pelo Programa de Pós-graduação em Psicologia Clínica e Cultura do Departamento de Psicologia e pesquisadora colaboradora da Universidade de Brasília (UnB) - Brasília-Brasil. Docente permanente do Programa de Mestrado Profissional em Ciências para 
a Saúde da Escola Superior de Ciências da Saúde

(ESCS), Psicóloga clínica e hospitalar da Secretaria de

Estado de Saúde do Distrito Federal - SES-DF.

E-mail: alearrais@gmail.com

Endereço para envio de correspondência: SHIS - QI

16 conj 02 casa 32. Lago Sul - Brasília - DF - CEP

71.640 .220 .

Recebido 01/10/2014

Aprovado 11/11/2016

Received 10/01/2014

Approved 11/11/2016

Recibido 01/10/2014

Aceptado 11/11/2016

Como citar: Almeida, N. M. C., \& Arrais, A. R. (2016). O pré-natal psicológico como programa de prevenção à depressão pós-parto. Psicologia: Ciência e Profissão, 36(4): 847-863. doi:10.1590/1982-3703001382014

How to cite: Almeida, N. M. C., \& Arrais, A. R. (2016). The psychological prenatal program as a prevention tool for postpartum depression. Psicologia: Ciência e Profissão, 36(4): 847-863. doi:10.1590/1982-3703001382014

Cómo citar:Almeida, N. M. C., \& Arrais, A. R. (2016). El programa prenatal psicológico como prevención de la depresión posparto. Psicologia: Ciência e Profissão, 36(4): 847-863. doi:10.1590/1982-3703001382014 